\title{
Processing and modeling of cellular solids for light-weight structures
}

\author{
T.G. Nieh
}

December 1997

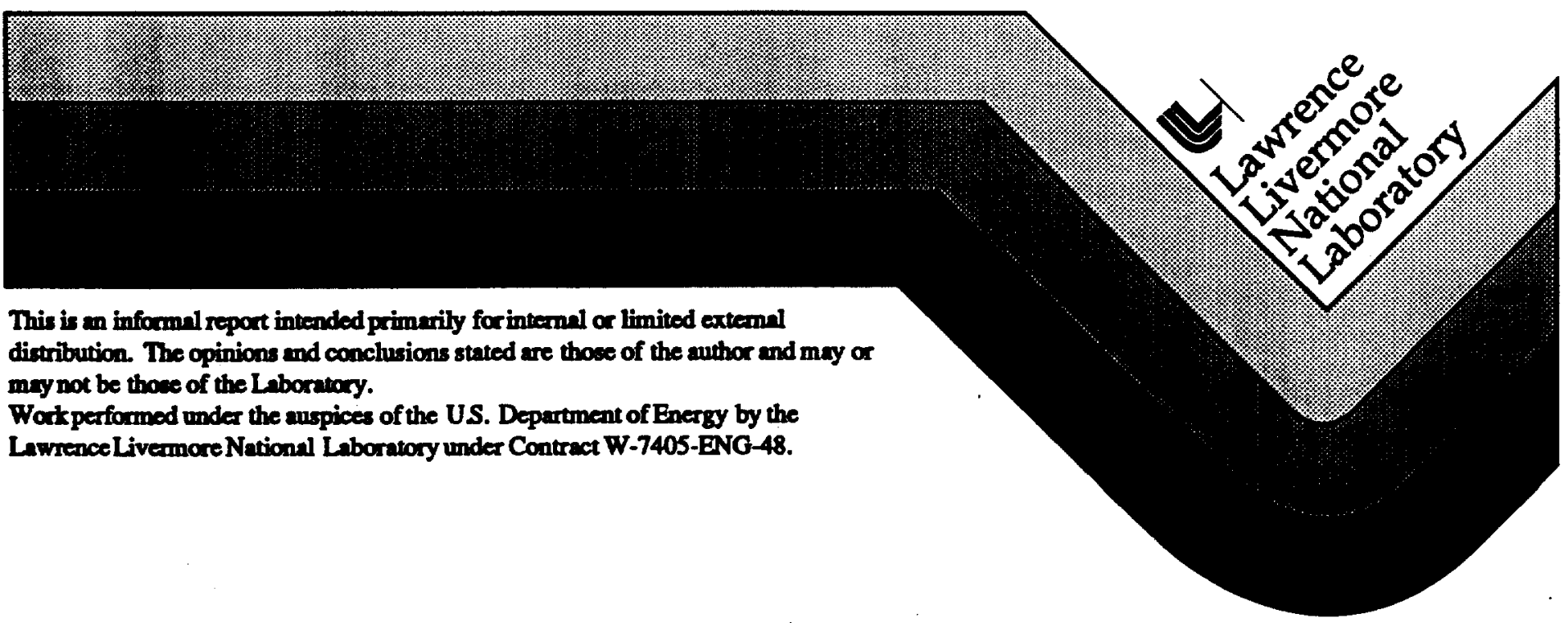




\section{DISCLAIMER}

This document was prepared as an account of work sponsored by an agency of the United States Government. Neither the United States Government nor the University of California nor any of their employees, makes any warranty, express or implied, or assumes any legal liability or responsibility for the accuracy, completeness, or usefulness of any information, apparatus, product, or process disclosed, or represents that its use would not infringe privately owned rights. Reference herein to any specific commercial product, process, or service by trade name, trademark, manufacturer, or otherwise, does not necessarily constitute or imply its endorsement, recommendation, or favoring by the United States Government or the University of California. The views and opinions of authors expressed herein do not necessarily state or reflect those of the United States Government or the University of California, and shall not be used for advertising or product endorsement purposes.

This report has been reproduced directly from the best available copy.

Available to DOE and DOE contractors from the Office of Scientific and Technical Information

P.O. Box 62, Oak Ridge, TN 37831

Prices available from (615) 576-8401, FTS 626-8401

Available to the public from the

National Technical Information Service

U.S. Department of Commerce

5285 Port Royal Rd.,

Springfield, VA 22161 


\section{Final Report}

Processing and Modeling of Cellular Solids for Light-Weight Structures

T.G. Nieh

Cellular solids (also known as porous solids) comprise a special class of materials. Such materials are common in nature; wood, cork, sponge and coral are examples. Recently man has also made his own cellular solids. For example, many honeycomb-like materials, made up of parallel, prismatic cells, are used for lightweight aerospace structural components. Polymeric foams have been used in everything from disposable coffee cups, packaging materials, to the crash padding of an aircraft cockpit. Advanced techniques now exist for foaming not only polymers, but metals and ceramics as well. These newer foams are increasingly used for catalysts (chemical), preforms for metal-matrix composites, thermal insulators and thermal shock resistant materials (thermal), acoustic dampers (acoustic), cushions, vibration reducers, and systems for absorbing the kinetic energy from impacts (mechanical). Their uses exploit the special combination of properties offered by cellular solids, properties which, ultimately, derive from their cellular structure. The objective of this proposed research is to develop processing techniques to produce metallic foams with controlled cellular structures and to understand and model the mechanical behavior of this special class of materials.

\section{Technical Accomplishments}

Metallic foams can be produced by using either casting or powder metallurgy methods. In our study, AA6101 aluminum foams (composition in weight \%: Al-0.6 $\mathrm{Mg}-0.5 \mathrm{Si}$ ) were fabricated using a directional solidification technique. An SEM micrograph of a foam with a relative density of $6 \%$ is shown in Figure 1. The foam has an open-celled structure and the cell geometry is remarkably uniform. The pore size and ligament diameter are approximately 2.5 and $0.4 \mathrm{~mm}$, respectively. The metallographic microstructure of the foam is also shown in Figure 2. It is a typical casting microstructure containing large grains and coarse inclusions. Grains are so large that they often extend across the entire ligament of a cell. The inclusions, 
analyzed by using EDX, are Fe-Si-Al particles commonly observed in a 6000 -series aluminum. No internal voids were observed in these ligaments.

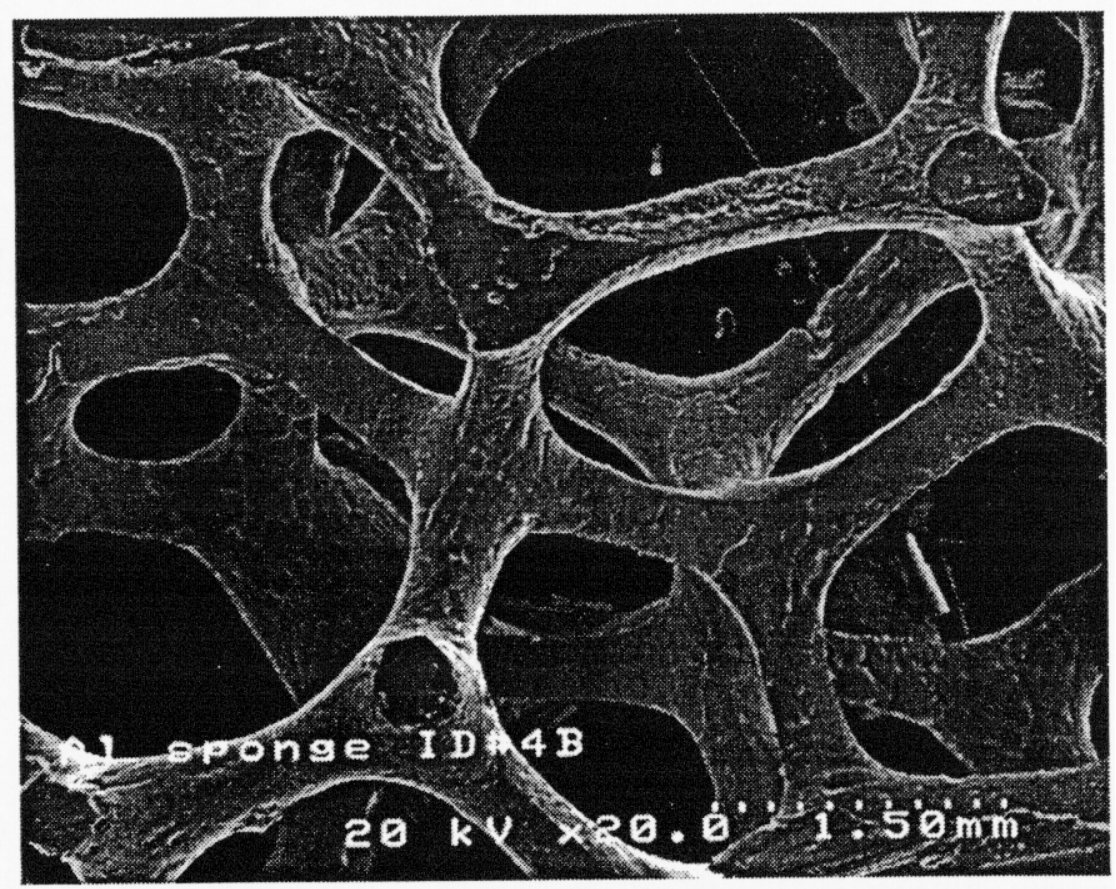

Fig. 1 SEM micrograph of an aluminum ( $\mathrm{Al} \mathrm{6010)} \mathrm{foam} \mathrm{with} \mathrm{a} 6 \%$ relative density.

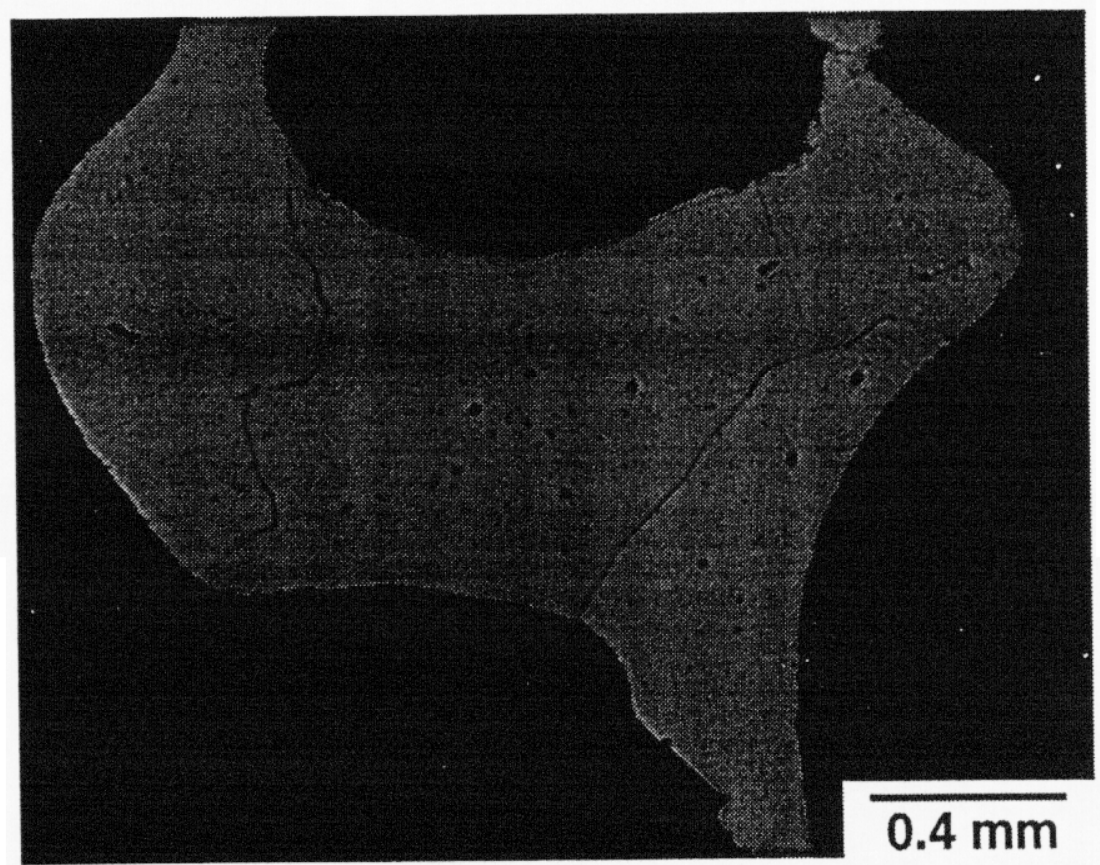

Fig. 2 The metallographic microstructure of the foam, showing a typical casting microstructure containing large grains and coarse inclusions.

The 3-dimensional (3-D) connectivity of the foam was examined using synchrotron $x$-ray tomography. $X$-ray tomographs of a porous aluminum foam 
(sample dimension: $10 \times 10 \times 10 \mathrm{~mm}$ ) were thresholded into binary images of metal and pore space (see Figure 3). Because of the exceptionally high contrast between metal and pore space there is a broad range of possible threshold values which lead to nearly identical structures. The foam shown in Figure 3 is predominantly opencelled, but there are a number of partially closed cells, solidified in place before the cell walls could drain away (Figure 4), indicating the nonequilibrium nature of the casting process. The edge connectivity number for the cellular structure is about three, similar to a tetrakaidecahedron. Although it is not obvious in Figure 3, cells are, in fact, slightly elongated along the solidification direction, resulting from the directional solidification process. Namely, the cell geometry is schematically illustrated in Figure 5.

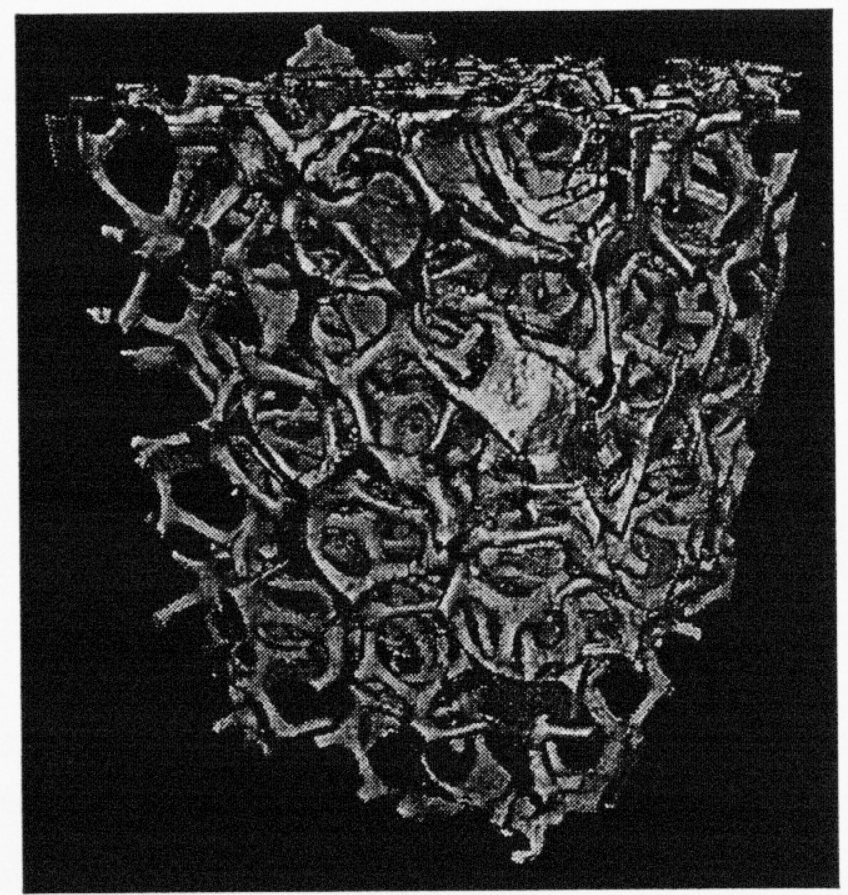

Fig. 3 Synchrotron tomography images of an aluminum foam at a resolution of $23 \mu \mathrm{m}$. The structure is predominately open-celled. 


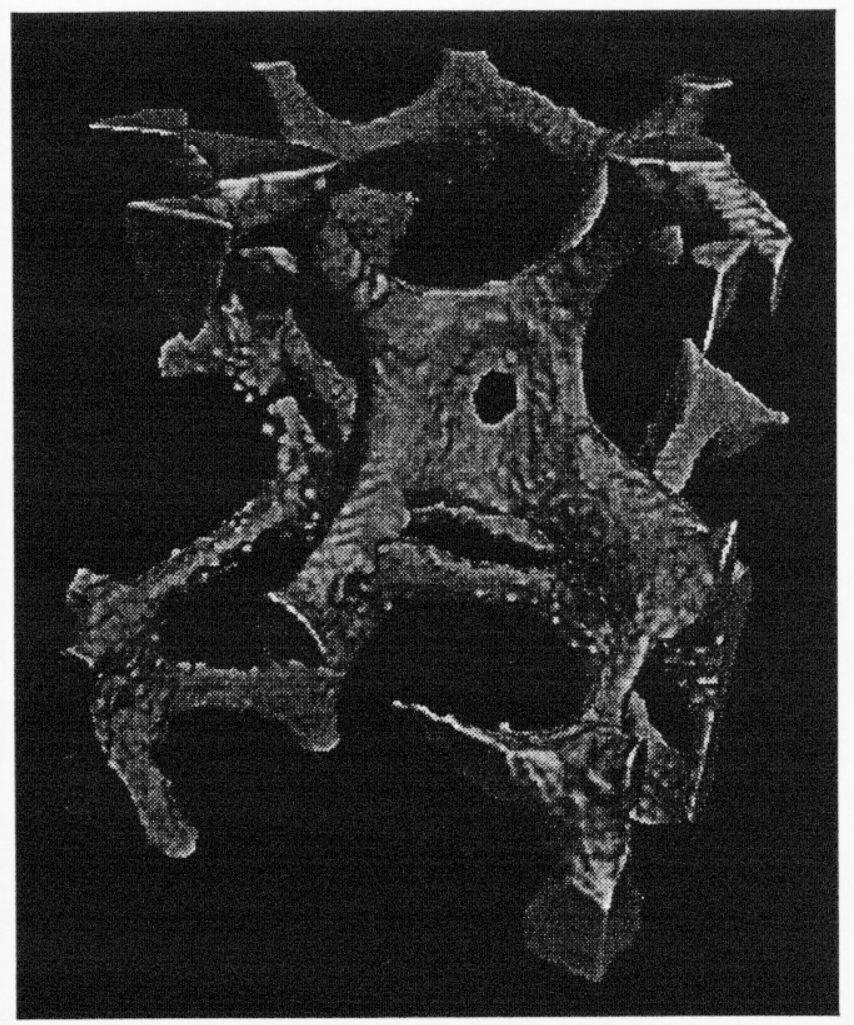

Fig. 4 An increased magnification of Figure 3 showing that some cell faces are fully or partially closed, due to insufficient drainage of the foam.

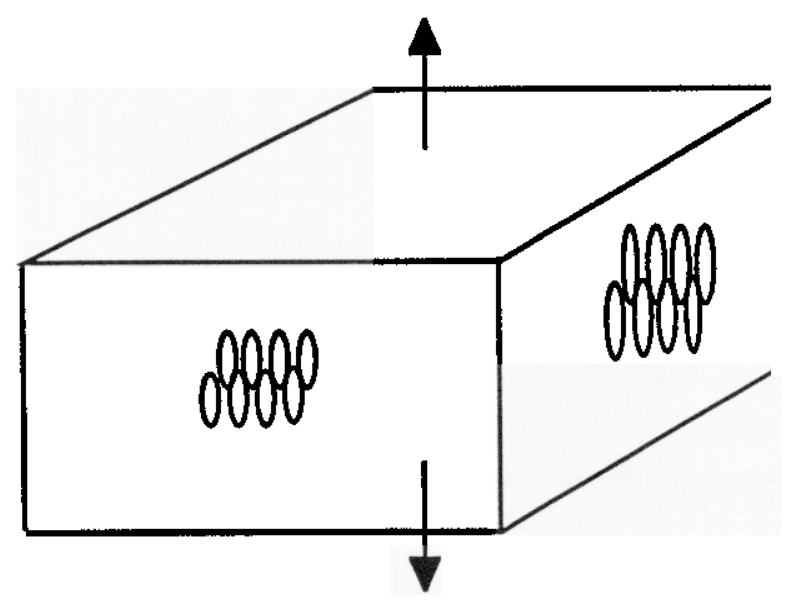

Fig. 5 Schematic illustration of the anisotropic cell geometry resulted from directional solidification (direction of solidification is indicated by arrows).

Mechanical tests (compression) were performed on several aluminum foams. The compressive stress-strain curve obtained from a foam with a density of $10.3 \%$ is shown in Figure 6. The foam exhibits a small elastic region, followed by a stress plateau, apparently caused by the plastic yielding of cell ligaments. Densification (i.e. a sharp rise in stress) of the foam begins to occur when the compressive strain is about 0.5 . The average elastic modulus of the foam in the direction that is parallel to the solidification direction (Fig. 5) is $670 \pm 20 \mathrm{MPa}$. The plastic yield stress is about 
2.7 MPa. In comparison the average elastic modulus of the foam in the direction that is perpendicular to the solidification direction is $630 \pm 30 \mathrm{MPa}$. The plastic yield stress is about $2.1 \mathrm{MPa}$. It is noted that the analytical predictions for elastic modulus and yield strength, according to Equations 1 and 2, are 746 and $2.1 \mathrm{MPa}$, respectively. The predicted modulus is higher than the experimental values, but the predicted yield stress is slightly lower than the experimental data. The modulus and yield stress of $\mathrm{Al} 6101-\mathrm{T} 6$ are $70.3 \mathrm{GPa}$ and $193 \mathrm{MPa}$, respectively [1].

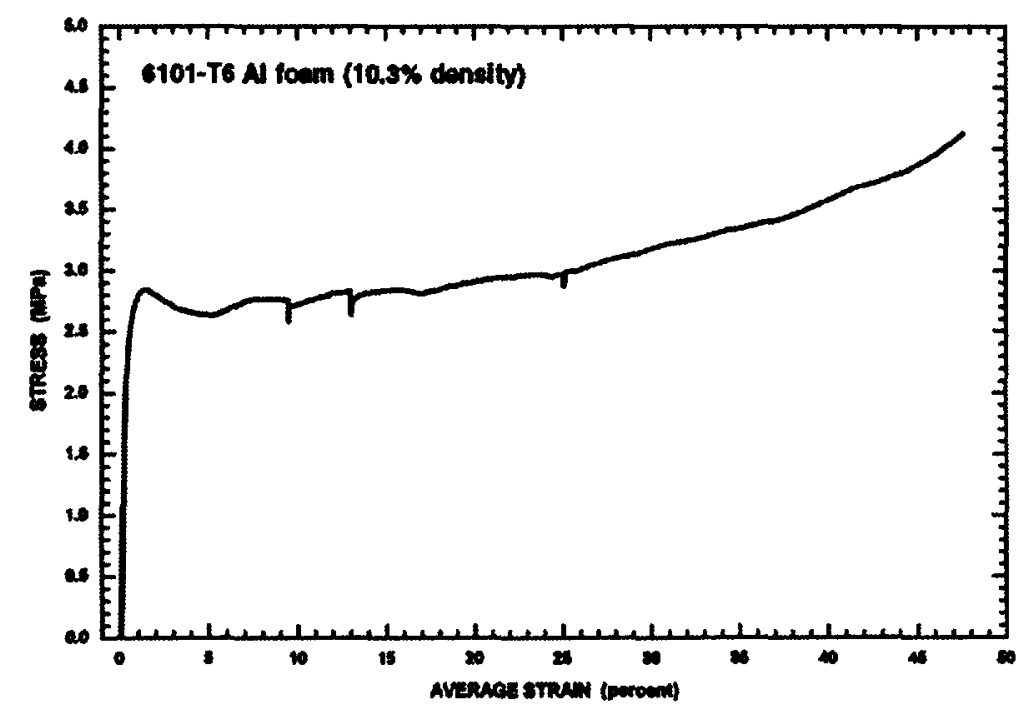

Fig. 6 Compressive stress-strain curve obtained from a 10.3\%-density Al 6101-T6 foam.

To simulate the mechanical properties of the foam, the thresholded images (Fig. 3) were used as input data to a finite-element method (FEM). It has been shown that a simple cubic lattice of nodes, connected by linear springs along the (100) and (110) crystallographic axes, can be used to efficiently discretize the continuum elastic equations, while maintaining the essential isotropy of the shear stresses [2]. In the present study, we extended this method into the element-by-element (EBE) formalism, in which the nodal forces derived from each element are summed on every cycle of an iterative conjugate-gradient solution. The main advantage of the EBE approach is that the storage requirements are of order $M$, the number of degrees of freedom, rather than $M^{2}$. It is therefore ideally suited to analyze $x$-ray tomographs which contain a large number of identical elements. Moreover, the stiffness matrix derived from the spring-network model is much simpler than that derived from strain-energy minimization and the nodal forces can be calculated 
about 10 times faster. This increased efficiency makes it possible to study structures of up to $10^{7}$ elements routinely.

The Young's modulus of the porous foam was calculated along the orthogonal axes of the cube; the data shown in Table 1 have been normalized by the Young's modulus of the fully-dense material, $E_{0}$. Most calculations used the full resolution of the tomographic image, and contained about 6 million elements. To test the sensitivity of the calculated stiffness to resolution, the tomographic image was rebinned from a resolution $\alpha=23.4 \mu \mathrm{m}$ to $\alpha=46.8 \mu \mathrm{m}$ and the elastic constants were recalculated. The data in Table 1 show that there is less than a $2 \%$ difference in the calculated stiffness at the two resolutions. Elastic constants calculated by FEM also depend on the boundary conditions imposed on the specimen: a fixed grip boundary condition, where the lateral displacements on the load surfaces are fixed, inevitably leads to a larger elastic modulus than free grips, where these displacements are allowed to relax freely. The FEM results in Table 1 show variations from $15 \%-20 \%$ between the extreme cases of fixed grips and free grips.

Table 1: The effects of voxel size ( $\alpha$ ) and boundary conditions on the calculated effective moduli for the aluminum foam

\begin{tabular}{|c|cccccc|}
\hline \multicolumn{3}{|c|}{ Fixed Grips } & \multicolumn{3}{c|}{ Free Grips } \\
\hline$\alpha(\mu \mathrm{m})$ & $E_{1} / E_{o}(\%)$ & $E_{2} / E_{o}(\%)$ & $E_{3} / E_{o}(\%)$ & $E_{1} / E_{o}(\%)$ & $E_{2} / E_{o}(\%)$ & $E_{3} / E_{o}(\%)$ \\
\hline 46.8 & 0.814 & 0.794 & 0.888 & 0.693 & 0.704 & 0.733 \\
\hline 23.4 & 0.811 & 0.802 & 0.898 & 0.695 & 0.709 & 0.743 \\
\hline
\end{tabular}

As noted in Table 1, the stiffnesses in the direction perpendicular to the solidification $\left(E_{1}\right.$ and $\left.E_{2}\right)$ are almost identical. But, the calculated stiffnesses do show a small but significant elastic anisotropy in the foam; the Young's modulus along the $\left(\mathrm{E}_{\mathrm{o}}\right)$ axis of the foam, corresponding to the direction parallel to solidification $\left(E_{3}\right)$, is $5-10 \%$ larger than that calculated along the other two axes (i.e. $E_{1}$ and $E_{2}$ ). This agrees well with the experimental observations. Specifically, measured stiffness anisotropy is about $6 \%(670 \mathrm{MPa}$ in the solidification direction versus $630 \mathrm{MPa}$ in the transverse direction). The experimental data were obtained from testing $75 \times 75 \times 50 \mathrm{~mm}$ specimens. In contrast, theoretical stiffness calculations were performed on a $10 \times 10 \times 10 \mathrm{~mm}$ specimen. It is particularly noted that experimental measurements on cellular solids must be conducted on a sample sufficiently large. This is to minimize the effect of free surfaces where ligaments are broken. 
To compare calculations and experiments from samples with the same dimension, we attempted to model in situ boundary conditions on a small piece of foam surrounded by a much larger specimen. One approach to this problem is to use periodic boundary conditions, with the small specimen representing a single unit cell of a macroscopic structure. To construct a connected periodic specimen we must first add a mirror image of the specimen at each of three orthogonal faces. The resulting 8-fold larger volume is a suitable unit cell for an infinite periodic sample. We have calculated the elastic constants of this specimen to compare with experimental data. A useful computational trick allows us to use the original volume set with a special boundary condition, which constrains the normal displacements on each surface and leaves the tangential displacements free to relax; the constraint on the normal displacement has the same effect as adding a mirror image of the volume set. The calculated Young's moduli $\left(E_{1}, E_{2}\right.$, and $\left.E_{3}\right)$ were, for a confined compression test, 831, 825, and $992 \mathrm{MPa}$. However the experimental measurements were for unconfined compression, so off-diagonal elastic constants (i.e. $\left.E_{x x y y}\right)$ were used to convert the results to unconfined compression. The calculated results for unconfined compression, on the other hand, were 564, 570, and $631 \mathrm{MPa}$. These results compare more favorably with experimental results of $630 \pm 30$ $\left(E_{1}\right.$ and $\left.E_{2}\right)$ and $670 \pm 20 \mathrm{MPa}\left(E_{3}\right)$.

\section{Summary}

In this project, we demonstrated the success of producing uniform AA6101 aluminum foams (composition in weight \%: Al-0.6 Mg-0.5 Si) by using a directional solidification technique. The 3-D morphology of the foams was examined using synchrotron $x$-ray tomography and the results revealed relatively uniform, opencelled structures. The mechanical (compression) behavior of the foams was also characterized. The stress-strain curves exhibited a typical three-stage behavior: elastic, nearly-perfect plastic (i.e. with a stress plateau), and densification. The elastic moduli of a $10 \%$-dense foam in the directions that are transverse and parallel to the solidification direction were measured to be 630 and $670 \mathrm{MPa}$, respectively. Theoretical calculations of the modulus using a FEM method with the element-byelement (EBE) formalism were also carried out. The calculated values of approximately 570 and $630 \mathrm{MPa}$, compared favorably with the experimental data.

\section{Publication}


T.G. Nieh, T. Ladd, J. Kinney, and J. Wadsworth, 'Morphology and Elastic Properties of Aluminum Foams Produced by a Casting Technique,' Scr. Mater., (1998). - in press

\section{References}

1. ASM, Metals Handbook, Ninth Edition, Volume 2-Properties and Selection: Nonferrous Alloys and Pure Metals, American Society for Metals, 1980.

2. A.J.C. Ladd and J. Kinney, Physica A, 240 (1997) 349. 


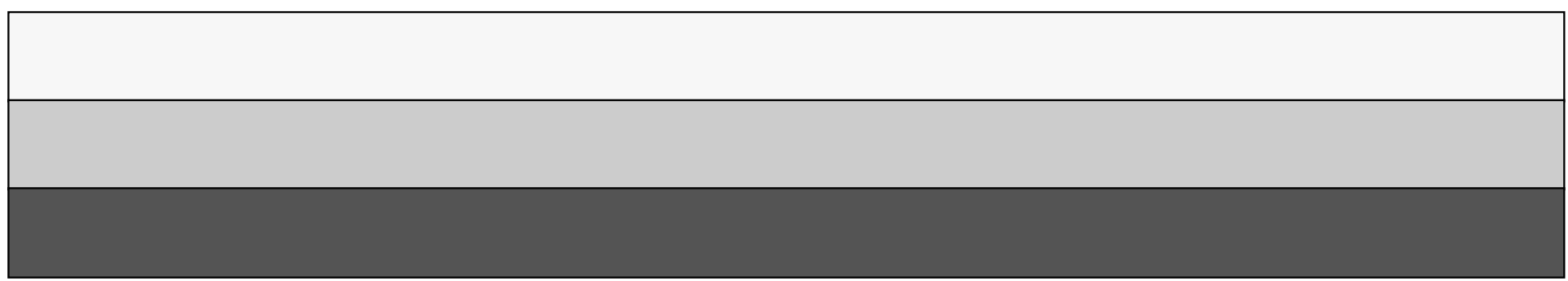

